\title{
Cytopathic Change and Inflammatory Response of Human Corneal Epithelial Cells Induced by Acanthamoeba castellanii Trophozoites and Cysts
}

\author{
Hae-Jin Sohn†, Ga-Eun Seo ${ }^{\dagger}$, Jae-Ho Lee, A-Jeong Ham, Young-Hwan Oh, Heekyoung Kang, Ho-Joon Shin* \\ Department of Microbiology, Ajou University School of medicine, and Department of Biomedical Science, Graduate School of Ajou University, \\ Suwon 16499, Korea
}

\begin{abstract}
Acanthamoeba castellanii has ubiquitous distribution and causes primary acanthamoebic keratitis (AK). AK is a common disease in contact lens wearers and results in permanent visual impairment or blindness. In this study, we observed the cytopathic effect, in vitro cytotoxicity, and secretion pattern of cytokines in human corneal epithelial cells (HCECs) induced by A. castellanii trophozoites and/or cysts. Morphological observation revealed that panked dendritic HCECs co-cultured with amoeba cysts had changed into round shape and gradually died. Such changes were more severe in co-culture with cyst than those of co-cultivation with trophozoites. In vitro cytotoxicity assay revealed the highest cytotoxicity to HCECs in the co-culture system with amoeba cysts. A. castellanii induced the expression of IL-1a, IL-6, IL8, and CXCL1 in HCECs. Secreted levels of IL-1a, IL-6, and IL-8 in HCECs co-cultured with both trophozoites and cysts were increased at an early incubation time ( 3 and $6 \mathrm{hr}$ ). These results suggested that cytopathic changes and pro-inflammatory cytokines release of HCECs in response to $A$. castellanii, especially amoebic cysts, are an important mechanism for AK development.
\end{abstract}

Key words: Acanthamoeba castellanii, acanthamoebic keratitis, human corneal epithelial cell, cytotoxicity, pro-inflammatory cytokine

\section{INTRODUCTION}

Free-living Acanthamoeba spp. are distributed worldwide, especially in soil, fresh water, water tank of cooling tower, and contact lens container [1]. Acanthamoeba castellanii can cause clonic granulomatous amoebic encephalitis (GAE) while A. castellanii and A. polyphaga can induce acanthamoebic keratitis (AK) [2-5]. A. castellanii generally causes AK through oxygen deficiency, weak stratum basal tears, and excessive corneal stimulation in contact lens wear. When A. castellanii is inoculated into eye via contact lens, it can infect corneal epithelial cell and induce inflammation (keratitis) [6].

The first case of AK was reported in 1973. Since then, about 5,000 cases of AK have been recorded in USA [7]. In South Korea, about 43 cases of AK were reported in 2008. In 154 cases of Austrian AK, 89\% persons were contact lens wearers and

- Received 11 March 2019, revised 17 April 2019, accepted 18 April 2019.

*Corresponding author (hjshin@ajou.ac.kr)

${ }^{\dagger}$ These authors contributed equally to this work.

(c) 2019, Korean Society for Parasitology and Tropical Medicine

This is an Open Access article distributed under the terms of the Creative Commons Attribution Non-Commercial License (http://creativecommons.org/licenses/by-nc/4.0) which permits unrestricted non-commercial use, distribution, and reproduction in any

medium, provided the original work is properly cited.
19\% had corneal transplantation [8]. Some commercial contact lens container solution has less effective amoebicidal activity, because cell wall of acanthamoebic cyst has resistance to disinfection solution commonly used in the house $[9,10]$. Due to increasing demand for contact lens, the problem of AK is becoming a social issue while contentable prevention or treatment drugs have not been developed yet [11,12].

Acanthamoeba sp. can mainly proliferate on contact lens surface after contact lens storage solution is contaminated, resulting in eye infection [6]. Although wearing contact lens is a major cause of AK, most cases of AK in experimental animals are induced by the presence of corneal damage before the exposure of pruritic amoeba $[13,14]$. Nevertheless, intraocular infections do not easily occur in animal experiments due to strong neutrophil reaction and increased resistance to nutritional and delayed infections, although A. castellanii trophozoites can penetrate corneal endothelium [12].

On the other hand, it has been reported that $\mathrm{AK}$ is easily induced by caustic amoebic cysts because of their strong resistance to disinfectant chemicals, the expression of cysteine proteinase, and so on $[9,10]$. However, the development mechanism of AK differs depending on the infection type of amoeba 
in trophozoic or cystic form because there are not enough studies on AK development. In this study, we investigated the in vitro cytotoxicity of A. castellanii trophozoites or cysts to target corneal cells and cytokine secretion in target cells by culturing in order to elucidate the mechanism of AK development.

It is possible to hypothesize that there is a difference in the development mechanism of AK according to infectious type of amoeba, trophozoite or cyst. Therefore, immunological studies on cytopathological and inflammatory reaction of host cells co-cultured with amoeba trophozoites or cysts are necessary. In this study, we investigated morphologic cytopathic effects and in vitro cytotoxicity by culturing $A$. castellannii trophozoites or cysts with corneal epithelial cells as target cells. Secretion patterns of pro-inflammatory cytokines were then observed.

\section{MATERIALS AND METHODS}

\section{Culture and encystation of $A$. castellanii}

A. castellanii trophozoites were axenically cultured with PYG medium ( $2 \%$ proteose peptone, $0.2 \%$ yeast extract, $0.1 \mathrm{M}$ glucose, $4 \mathrm{mM} \mathrm{MgSO}_{4} 7 \mathrm{H}_{2} \mathrm{O}, 0.4 \mathrm{mM} \mathrm{CaCl}_{2}, 3.4 \mathrm{mM}$ sodium citrate $2 \mathrm{H}_{2} \mathrm{O}, 50 \mu \mathrm{M} \mathrm{Fe}\left(\mathrm{NH}_{4}\right)_{2}\left(\mathrm{SO}_{4}\right) 6 \mathrm{H}_{2} \mathrm{O}, 2.5 \mathrm{mM} \mathrm{KH}_{2} \mathrm{PO}_{4}, 2.5$ $\mathrm{mM} \mathrm{Na}_{2} \mathrm{HPO}_{4}, \mathrm{pH} 6.5$ ) at $25^{\circ} \mathrm{C}$ [15]. Cyst formation was done according to previous method [16]. Briefly, A. castellanii trophozoites were washed with PBS (pH 7.4) twice, centrifuged at 1,500 rpm for $5 \mathrm{~min}$, and placed into 12-well plates $\left(5 \times 10^{5}\right.$ cells/ml) with encystment medium ( $95 \mathrm{mM} \mathrm{NaCl}, 5 \mathrm{mM} \mathrm{KCl}$, $8 \mathrm{mM} \mathrm{MgSO}_{4}, 0.4 \mathrm{mM} \mathrm{CaCl}_{2}, 1 \mathrm{mM} \mathrm{NaHCO}{ }_{3}, 20 \mathrm{mM}$ Tris$\mathrm{HCl}, \mathrm{pH}$ 9.0). After induction of cyst formation, all remaining trophozoites were removed by treatment with $0.05 \%$ N-lauroylsarcosine sodium salt solution (Sarcosyl; Sigma Chemical Co., St Louis, Missouri, USA) at room temperature for $20 \mathrm{~min}$ $[17,18]$.

\section{Cultivation of human corneal epithelial cells}

Human corneal epithelial cells (HCECs) were cultured with keratinocyte basal medium (KBM; Lonza, Walkersville, Maryland, USA) at $37^{\circ} \mathrm{C}$ in a $5 \% \mathrm{CO}_{2}$ incubator. HCECs were cultured in $75-\mathrm{cm}^{2}$ flasks (Nunc, Naperville, Illinois, USA) until they became monolayer. Then $5 \mathrm{ml}$ of trypsin-EDTA (1X) solution was added. Cells were harvested, washed with PBS (pH 7.4) 3 times, and placed into 6-well plates at density of $5 \times 10^{5}$ cells $/ \mathrm{ml}$. After incubation at $37^{\circ} \mathrm{C}$ for $3 \mathrm{hr}$, monolayer-cultured HCECs were used for experiments.

\section{Cytopathic changes of HCECs co-cultured with A. castellanii}

HCECs cultured in 6-well plates $\left(5 \times 10^{5}\right.$ cells $\left./ \mathrm{ml}\right)$ were cocultured with A. castellanii trophozoites only $\left(5 \times 10^{5} \mathrm{cells} / \mathrm{ml}\right)$, cysts only $\left(5 \times 10^{5}\right.$ cells $\left./ \mathrm{ml}\right)$, or both trophozoites and cysts (each $2.5 \times 10^{5} \mathrm{cells} / \mathrm{ml}$ ) at $37^{\circ} \mathrm{C}$ in a $5 \% \mathrm{CO}_{2}$ incubator for 3,6 , 9,12 , and 24 hr. After culturing, to observe cytopathic effects in target cells cultured with trophozoites or cysts of amoeba, numerical and morphological changes were determined by phase contrast microscopy (Olympus, Shinjuku, Tokyo, Japan). To determine in vitro cytotoxicity of amoeba against target cells, the amount of lactate dehydrogenase (LDH) released from cultured HCECs was measured using Cytotox 96 non-radioactive cytotoxicity assay (Promega, Madison, Wisconsin, USA) as described previously [19].

\section{Cytokines expression from HCECs co-cultured with A. castellanii}

To determine expression levels of cytokine genes from target cells in the above culture system, RT-PCR was carried out for interleukin 1 alpha (IL-1 $\alpha$ ), interleukin 6 (IL-6), and interleukin 8 (IL-8) genes. Briefly, total RNA was isolated from cultured HCECs with RNeasy mini kit (QIAGEN, Valencia, California, USA). The CDNA was subjected to RT-PCR with genespecific primers (Table 1 ) targeting human IL-1 $\alpha$, IL-6, IL-8 using a Quantstudio 3 real-time RT-PCR instrument (Thermo Fisher Scientific, Singapore). PCR condition was as follows: 40 cycles of denaturing at $95^{\circ} \mathrm{C}$ for $5 \mathrm{sec}$, annealing at $60^{\circ} \mathrm{C}$ for 34 sec, and extension at $72^{\circ} \mathrm{C}$ for $30 \mathrm{sec}$.

\section{Levels of cytokines released from HCECs co-cultured with $A$. castellanii}

To determine levels of cytokines (IL-1 $\alpha$, IL-6, and IL-8) secreted from target cell, LISA kits (R\&D Systems, Minneapolis, Minnesota, USA) were used following the manufacturer's instructions. Briefly, each $100 \mu \mathrm{l}$ of supernatant from HCECS cocultured with amoebic trophozoites or cysts was placed into a 96-well polystyrene microplate containing $100 \mu \mathrm{l}$ of assay di-

Table 1. Primers used for real time RT-PCR

\begin{tabular}{lcc}
\hline Gene & Forward primer $\left(5^{\prime}\right.$ to $\left.3^{\prime}\right)$ & \multicolumn{1}{c}{ Reverse primer $\left(5^{\prime}\right.$ to $\left.3^{\prime}\right)$} \\
\hline Actin TGGCACCCAGCACAATGAA & CTAAGTCATAGTCCGCCTAG \\
IL-1a GAATGACGCCCTCATCAAAGT TCATCTTGGGCAGTCACATACA \\
IL-6 & AAGCCAGAGCTGTGCAGATG & TGTCCTGCAGCCACTGGTTC \\
IL-8 & GCAGTITGCCAAGGAGTGTC & TTCTGTGTTGGCGCAGTGTG \\
\hline
\end{tabular}


luent RD1W and reacted at room temperature for $2 \mathrm{hr}$. After washing with wash buffer four times, $200 \mu \mathrm{l}$ of human IL-6 conjugate was added to the well on and reacted at room temperature for $24 \mathrm{hr}$. After washing, $50 \mu \mathrm{l}$ of substrate solution was added and the reaction absorbance was measured at wavelength of $450 \mathrm{~nm}$ on an ELISA reader.

\section{Statistical analysis}

This experiment was repeated three times or more. Difference between experimental and control groups was analyzed using Student's $t$-test. Statistical significance was accepted at $P<0.05$.

\section{RESULTS}

\section{Encystation of $A$. castellanii}

Results of cyst formation of A. castellanii trophozoites cul- tured in encystment media revealed round precysts consisting of a single cell wall were at $24 \mathrm{hr}$. From $48 \mathrm{hr}$ after induction of cyst formation, complete cysts with double-walled polygons were formed. After inducing cyst formation for $72 \mathrm{hr}$, complete cysts of polygonal double wall were observed (Fig. 1). They were used for subsequent experiments.

\section{Cytopathic changes of HCECs induced by $A$. castellanii}

Results of cytopathic changes of HCECs co-cultured with A. castellanii trophozoites and/or cysts revealed that the number of HCECs was decreased over time in all experimental groups (cultured with trophozoites only, cysts only, or both trophozoites and cysts) compared to that of control panked dendritic HCECs. In addition, round or dissolving cell wall shapes were observed in all experimental groups (Fig. 2). Particularly, after $6 \mathrm{hr}$ of culture with amoebic trophozoites, A. castellanii tro-

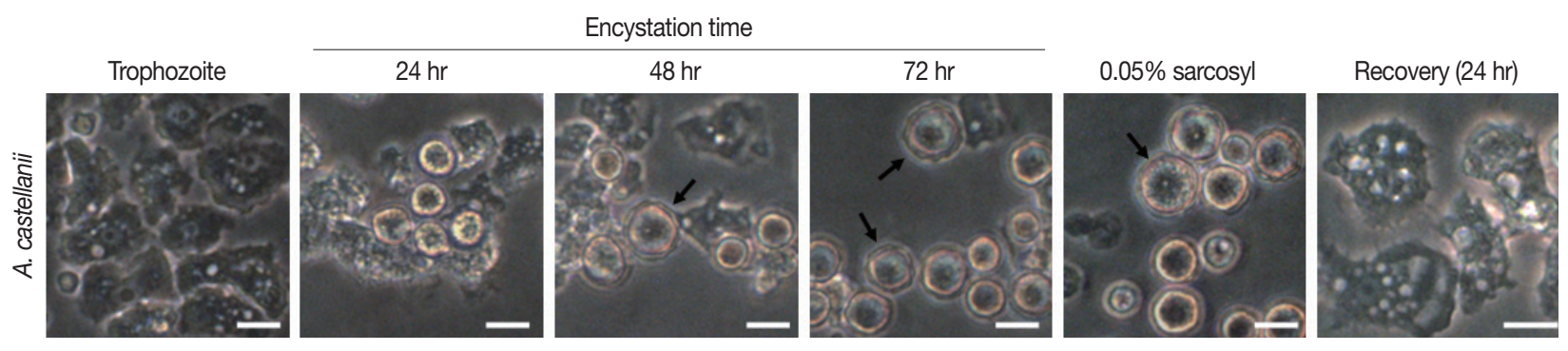

Fig. 1. Morphologic change of $A$. castellanii trophozoites into pre- and mature cysts by induction with encystment medium. Arrows indicate double-walled mature cysts. Scale bar $=20 \mu \mathrm{m}$.

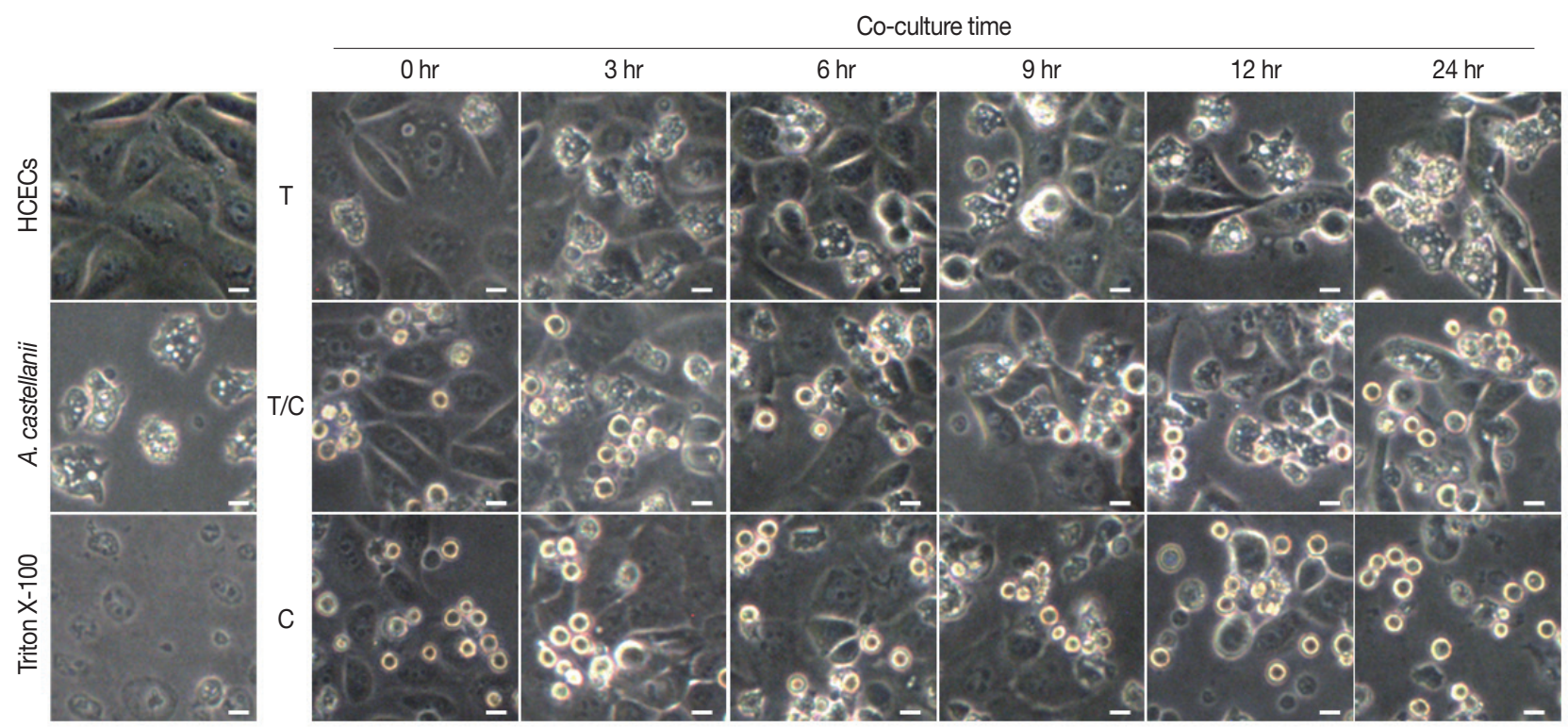

Fig. 2. Cytopathic changes of HCECs co-cultured with A. castellanii. T, trophozoite only; T/C, trophozoite and cyst; C, cyst only. Scale bar $=20 \mu \mathrm{m}$. 
phozoites were attached to HCECs for phagocytosis. After 12 and $24 \mathrm{hr}$ of culture, more attachments were observed. Additionally, the number of target cells was decreased significantly after $24 \mathrm{hr}$ of incubation (Fig. 2). For HCECs cultured with amoeba cysts, they transformed into long and rounded form after $12 \mathrm{hr}$ of culture. After $24 \mathrm{hr}$ of culture, HCECs were not adhered to the bottom of the plate any more, which were floating and dissolved or dead (Fig. 2).

\section{In vitro cytotoxicity of $A$. castellanii to HCECs}

Results of in vitro cytotoxicity of A. castellanii to HCECs based on LDH release assay revealed that amounts of LDH released from HCECs were increased over time in all experimental groups in comparison with those in control HCECs (Fig. 3). When trophozoites were cultured with HCECs, in vitro cytotoxicities of $A$. castellanii to HCECs after 3, 6, 9, 12, and 24 hr of incubation were $2.2,6.7,22.6,28.2$, and $67.6 \%$ respectively (Fig. 3). When both trophozoites and cysts were cultured with HECECs, in vitro cytotoxicities of A. castellanii to HCECs were 3.0, 9.0, 28.0, 34.2, and $74.0 \%$ after $3,6,9,12$, and $24 \mathrm{hr}$ of incubation, respectively (Fig. 3). When cysts only were cultured with HCECs, in vitro cytotoxicities of A. castellanii to HCECs were 3.6, 11.3, 33.0, 42.6,
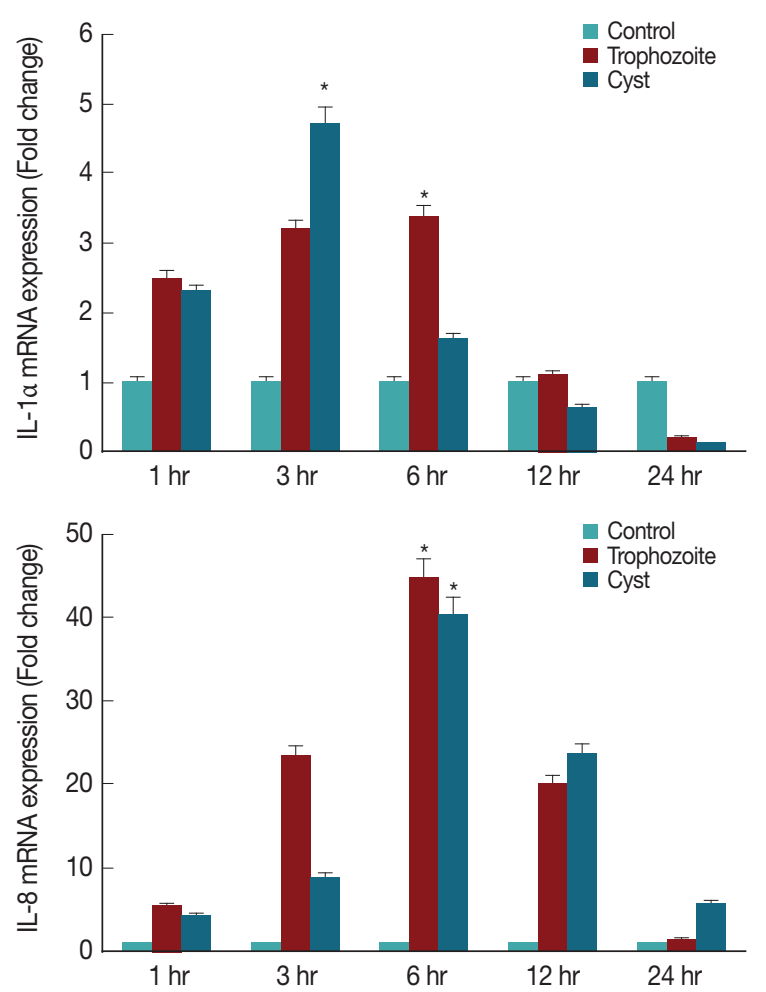

and $86.8 \%$ after $3,6,9,12$, and $24 \mathrm{hr}$ of incubation, respectively (Fig. 3). When only cysts were cultured with HCECs, the amoebic in vitro cytotoxicity was the highest.

\section{mRNA expression levels of cytokines in HCECs induced by $A$. castellanii}

To determine what kind of cytokines were secreted in corneal epithelial cells, lysates of HCECs co-cultured with A. castellanii trophozoites or cysts were subjected to real time RT-PCR for

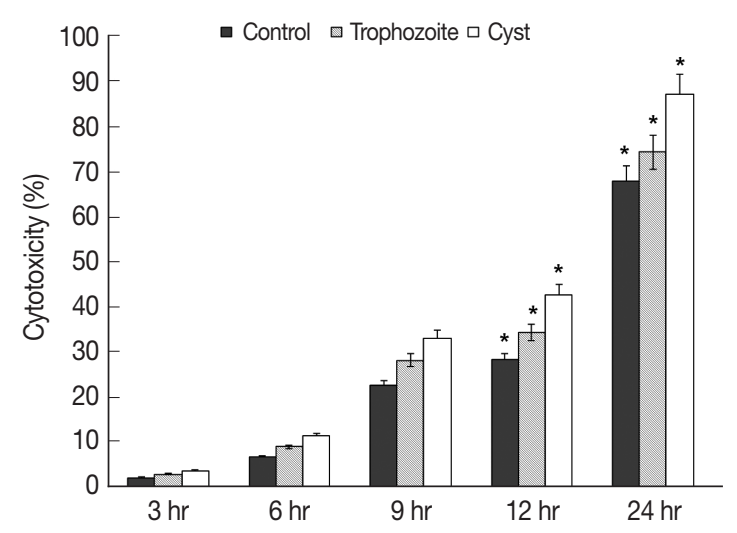

Fig. 3. In vitro cytotoxicity of $A$. castellanii to HCECs by LDH assay. Co-cultured with trophozoites and cysts. ${ }^{*} P<0.005$.
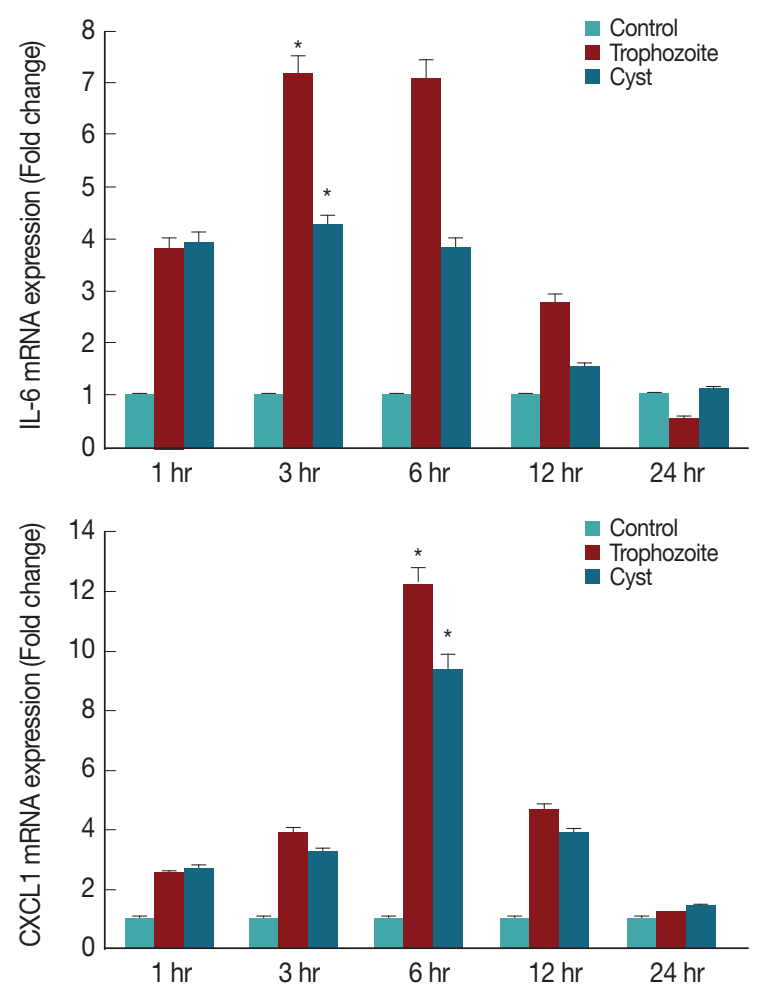

Fig. 4. Expression of cytokines in HCECs co-cultured with $A$. castellanii trophozoites or cysts. ${ }^{*} P<0.005$. 
detection of IL-1 $\alpha$, IL-6, IL-8, and CXCL1 genes. Results showed that mRNA levels of IL-1 $\alpha$, IL-6, IL-8, and CXCL1 in HCECs cultured with trophozoites were significantly increased after $3 \mathrm{hr}$, reaching the highest level after $6 \mathrm{hr}$. They were then decreased over time (Fig. 4). When HCECs were co-cultured with only ameba cysts, mRNA levels of IL-6, IL-8, and CXCL1 were significantly increased after $3 \mathrm{hr}$, reaching the highest expression levels after 6 hr of incubation (Fig. 4).

\section{Cytokines secreted from HCECs induced by $A$. castellanii}

Since IL-6 and IL-8 mRNA expression levels in HCECs cocultured with A. castellanii were increased, ELISA was performed to observe secretion levels of cytokines IL- 6 and IL-8 induced by and A. castellanii. When HCECs were cultured with amoeba trophozoites, amounts of IL-6 secreted into cultured medium after 1, 3, 6, 12, and $24 \mathrm{hr}$ of incubation were 91.25, $893.58,1042.58,620.25$, and $133.25 \mathrm{pg} / \mathrm{ml}$, respectively. Amounts of secretion started to increase at $3 \mathrm{hr}$ after culture, reaching the highest level at $6 \mathrm{hr}$ after culture. They were then gradually decreased (Fig. 5A). Amounts of IL-6 secreted from HCECs cultured with amoeba cysts after 1, 3, 6, 12, and $24 \mathrm{hr}$ were $80.25,457.25,484.92,438.58$, and $403.25 \mathrm{pg} / \mathrm{ml}$, respectively. IL-6 was highly secreted at $3 \mathrm{hr}$ after incubation. It was secreted the most at $6 \mathrm{hr}$ after incubation followed by gradual decrease (Fig. 5A). Amounts of IL-8 secreted to the culture medium from HCECs co-cultured with only amoeba trophozoites were 6.3, 25.97, 218.97, 292.97, and $380.97 \mathrm{pg} / \mathrm{ml}$ after 1, 3, 6, 12, and $24 \mathrm{hr}$ of incubation, showing a continuous increasing trend with increasing incubation time (Fig. 5B). When HCECs were cultured with amoeba cysts, amounts of IL-8 secreted into the culture medium were 16.3, 23.3, 128.97, 160.3 , and $303.63 \mathrm{pg} / \mathrm{ml}$ after 1, 3, 6, 12, and $24 \mathrm{hr}$ of incuba- tion, respectively, as showing an increasing trend with incubation time (Fig. 5B).

\section{DISCUSSION}

The incidence of AK is increasing with increasing number of contact lens wearers. Its initial diagnosis is difficult, and a variety of pathophysiological studies are needed to develop a contact storage solution effective to kill amoeba. In addition, definite therapeutic agents for AK are limited [20-23].

In the results of cytopathic effect and cytotoxicity of A. castellanii trophozoites on HCECs, the number of target cells was decreased with increasing incubation time. Such decrease in the total number of target cells is mainly due to amoebic phagocytosis. In the case of cystic type treatment, HCECs changed into a round and elongated shape over time with many dead cells, thereafter, showing a slightly different phenomenon from the case of trophozoites treatment.

The cytotoxicity of amoeba cysts to HCECs was higher than that of amoeba trophozoites. Their cytotoxicities were the strongest at $24 \mathrm{hr}$ after incubation (trophozoites, 67.6\%; cysts, $86.8 \%$ ). Cytopathic changes and death of target cells are probably due to cytolytic factors such as serine protease, metalloprotein protease, and cysteine protease secreted from A. castellanii [24-27]. The cytotoxicity was somewhat higher in the amoebic cyst co-culture, and then a further research is needed on the elucidation of these related materials. Like other mucosal epithelial cells, corneal epithelial cells can detect pathogenic microorganisms and engage in innate immune response that involves macrophage cells and neutrophils. It is known that macrophages and neutrophils play an essential role in the elimination of pathogens, resulting in an inflammatory reaction [28]. Neutro-
A

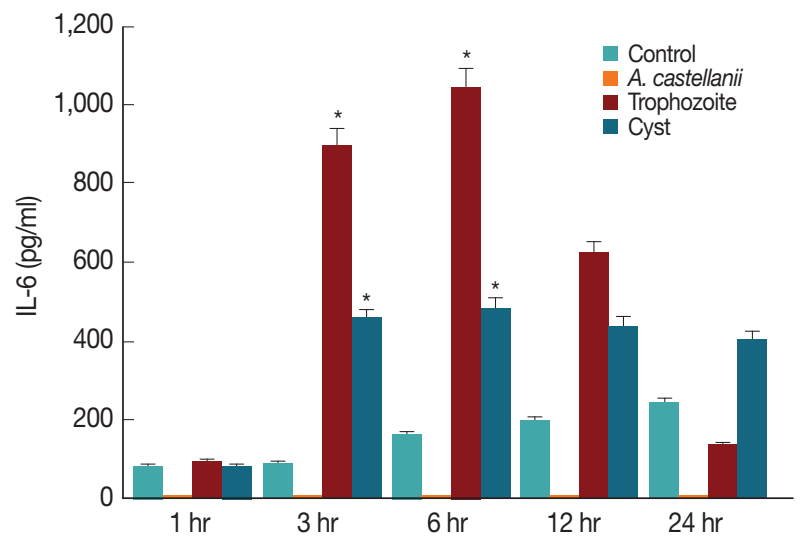

B

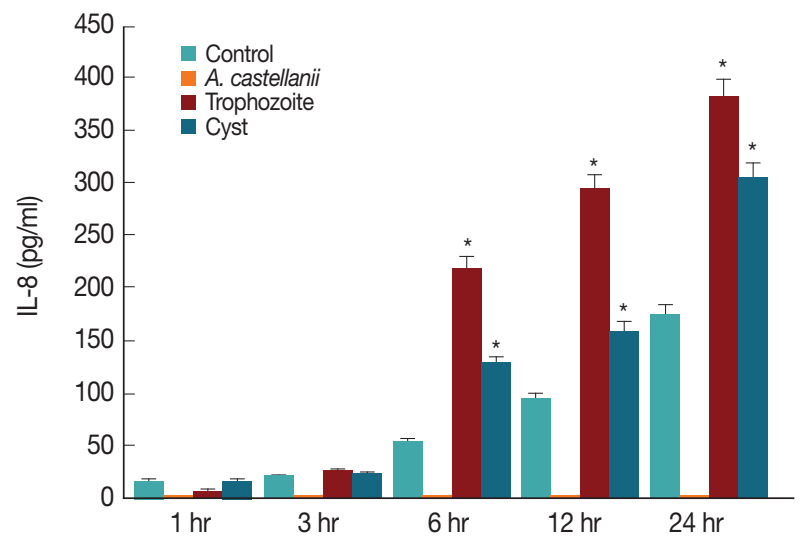

Fig. 5. Secretion of IL-6 (A) and IL-8 (B) from HCECs co-cultured with A. castellanii trophozoites or cysts. ${ }^{*} P<0.005$. 
phils of Chinese hamster corneal epithelial cells can kill amoeba trophozoites. When AK-induced hamster was treated with anti-MIP2 antibody, an inhibitor of macrophage inflammatory protein-2 (MIP-2), symptoms of AK were worse [22]. The production of IL-6 and IL-8 may cause barrier destruction of the corneal epithelium and inflammation of the ocular surface [29]. In this study, mRNA expression levels of IL-1 $1 \alpha$, IL-6, and IL-8 in HCECs cultured with A. castellanii cysts and trophozoites for 3 and $6 \mathrm{hr}$ were significantly higher than those in the control group. Especially, expression levels of IL-6 were decreased at 12 and $24 \mathrm{hr}$ post incubation with trophozoites. This might be due to a decrease in target cells caused by amoebic phagocytosis.

In the results of HCECs co-culture with amoeba cysts for 6 hr, IL-6 secretion levels were $484.92 \mathrm{pg} / \mathrm{ml}$, whereas 1,042.58 $\mathrm{pg} / \mathrm{ml}$ in culture with trophozoites. And then, they were rapidly increased with incubation time, showing difference between infectious (co-cultured) types of amoeba, as which trophozoites induce higher secretion than cysts. It is thought that some substances secreted from cysts have different cytopathic mechanisms, while amoebic trophozoites show cytopathic effects by phagocytosis as well as secretion of some cytolytic or immune materials. In addition, it is believed that there are different mechanisms between the cytopathic effect and the inflammatory reaction resulted of the immune response. The difference between A. castellanii cysts and trophozoites co-culture needs to be determined in further studies such as molecular cloning and characterization of some substances secreted differently between cysts and trophozoites.

In conclusion, these results suggest that cytopathic changes and pro-inflammatory cytokines release of HCECs in response to A. castellanii, in considering especially amoebic cysts contamination/infection, are an important mechanism for AK development.

\section{ACKNOWLEDGMENT}

This research was supported by a grant (2018R1D1A1B07047302) of the Basic Science Research Program through the National Research Foundation (NRF) funded by the Ministry of Science and ICT, Republic of Korea.

\section{CONFLICT OF INTEREST}

The authors declare no conflict of interest related to this study.

\section{REFERENCES}

1. Schuster FL, Visvesvara GS. Free-living amoebae as opportunistic and non-opportunistic pathogens of humans and animals. Int J Parasitol 2004; 34: 1001-1027.

2. Marciano-Cabral F, Cabral G. Acanthamoeba spp. as agents of disease in humans. Clin Microbiol Rev 2003; 16: 273-307.

3. Im K, Kim DS. Acanthamoebiasis in Korea: two new cases with clinical cases review. Yonsei Med J 1998; 39: 478-484.

4. van Klink F, Alizadeh H, Stewart GL, Pidherney MS, Silvany RE, He Y, McCulley JP, Niederkorn JY. Characterization and pathogenic potential of a soil isolate and an ocular isolate of Acanthamoeba castellanii in relation to Acanthamoeba keratitis. Curr Eye Res 1992; 11: 1207-1220.

5. Visvesvara GS, Stehr-Green JK. Epidemiology of free-living ameba infections. J Protozool 1990; 37 (suppl): 25-33.

6. Auran JD, Starr MB, Jakobiec FA. Acanthamoeba keratitis. A review of the literature. Cornea 1987; 6: 2-26.

7. Visvesvara GS. Amebic meningoencephalitides and keratitis: challenges in diagnosis and treatment. Curr Opin Infect Dis 2010; 23: 590-594.

8. Walochnik J, Scheikl U, Haller-Schober EM. Twenty years of acanthamoeba diagnostics in Austria. J Eukaryot Microbiol 2015; 62: 3-11.

9. Hiti K, Walochnik J, Haller-Schober EM, Faschinger C, Aspock H. Viability of Acanthamoeba after exposure to a multipurpose disinfecting contact lens solution and two hydrogen peroxide systems. Br J Ophthalmol 2002; 86: 144-146.

10. Zanetti S, Fiori PL, Pinna A, Usai S, Carta F, Fadda G. Susceptibility of Acanthamoeba castellanii to contact lens disinfecting solutions. Antimicrob Agents Chemother 1995; 39: 1596-1598.

11. Seal DV. Acanthamoeba keratitis update-incidence, molecular epidemiology and new drugs for treatment. Eye (Lond) 2003; 17: 893-905.

12. Hurt M, Niederkorn J, Alizadeh H. Effects of mannose on Acanthamoeba castellanii proliferation and cytolytic ability to corneal epithelial cells. Invest Ophthalmol Vis Sci 2003; 44: 3424-3431.

13. Hurt M, Apte S, Leher H, Howard K, Niederkorn J, Alizadeh H. Exacerbation of Acanthamoeba keratitis in animals treated with anti-macrophage inflammatory protein 2 or antineutrophil antibodies. Infect Immun 2001; 69: 2988-2995.

14. van Klink F, Alizadeh H, He Y, Mellon JA, Silvany RE, McCulley JP, Niederkorn JY. The role of contact lenses, trauma, and Langerhans cells in a Chinese hamster model of Acanthamoeba keratitis. Invest Ophthalmol Vis Sci 1993; 34: 1937-1944.

15. Visvesvara GS, Balamuth W. Comparative studies on related freeliving and pathogenic amebae with special reference to Acanthamoeba. J Protozool 1975; 22: 245-256.

16. Sohn HJ, Kang H, Seo GE, Kim JH, Jung SY, Shin HJ. Efficient Liquid Media for Encystation of Pathogenic Free-Living Amoebae. Korean J Parasitol 2017; 55: 233-238.

17. Moon EK, Xuan YH, Chung DI, Hong Y, Kong HH. Microarray analysis of differentially expressed genes between cysts and tro- 
phozoites of Acanthamoeba castellanii. Korean J Parasitol 2011; 49: 341-347.

18. Moon EK, Hong Y, Lee HA, Quan FS, Kong HH. DNA methylation of gene expression in Acanthamoeba castellanii encystation. Korean J Parasitol 2017; 55: 115-120.

19. Kim JH, Kim D, Shin HJ. Contact-independent cell death of human microglial cells due to pathogenic Naegleria fowleri trophozoites. Korean J Parasitol 2008; 46: 217-221.

20. Brown TJ, Cursons RT, Keys EA. Amoebae from antarctic soil and water. Appl Environ Microbiol 1982; 44: 491-493.

21. Cerva L, Serbus C, Skocil V. Isolation of limax amoebae from the nasal mucosa of man. Folia Parasitol (Praha) 1973; 20: 97-103.

22. Lyons TB, Kapur R. Limax amoebae in public swimming pools of albany, schenectady, and rensselaer counties, new york: their concentration, correlations, and significance. Appl Environ Microbiol 1977; 33: 551-555.

23. Paszko-Kolva C, Yamamoto H, Shahamat M, Sawyer TK, Morris G, Colwell RR. Isolation of amoebae and Pseudomonas and Legionella spp. from eyewash stations. Appl Environ Microbiol 1991;
57: 163-167.

24. Niederkorn JY, Alizadeh H, Leher H, McCulley JP. The pathogenesis of Acanthamoeba keratitis. Microbes Infect 1999; 1: 437-443.

25. Claerhout I, Kestelyn P. Acanthamoeba keratitis: a review. Bull Soc Belge Ophtalmol 1999; 274: 71-82.

26. Alizadeh H, Pidherney MS, McCulley JP, Niederkorn JY. Apoptosis as a mechanism of cytolysis of tumor cells by a pathogenic free-living amoeba. Infect Immun 1994; 62: 1298-1303.

27. Shin HJ, Cho MS, Kim HI, Lee M, Park S, Sohn S, Im KI. Apoptosis of primary-culture rat microglial cells induced by pathogenic Acanthamoeba spp. Clin Diagn Lab Immunol 2000; 7: 510514.

28. Kurpakus-Wheater M, Kernacki KA, Hazlett LD. Maintaining corneal integrity how the "window" stays clear. Prog Histochem Cytochem 2001; 36: 185-259.

29. Kernacki KA, Barrett RP, Hobden JA, Hazlett LD. Macrophage inflammatory protein-2 is a mediator of polymorphonuclear neutrophil influx in ocular bacterial infection. J Immunol 2000; 164: 1037-1045. 
